\title{
Multidimensionality of critical thinking: A holistic perspective from multidisciplinary educators in Karachi, Pakistan
}

\author{
Shanaz Hussein Cassum ${ }^{1}$, Profetto-McGrath Joanne ${ }^{2}$, Gul, Raisa Begum ${ }^{1}$, Ashraf Dilshad ${ }^{3}$, \\ Kauserali Syeda ${ }^{4}$
}

1. School of Nursing and Midwifery, Aga Khan University, Pakistan. 2. Faculty of Nursing, University of Alberta, Canada. 3. Institute for Educational Development, Aga Khan University, Pakistan. 4. Medical College, Aga Khan University, Pakistan

Correspondence: Shanaz Hussein Cassum. Address: School of Nursing and Midwifery, Aga Khan University, Pakistan. Email: shanaz.cassum@aku.edu.

Received: September 2, 2012

Accepted: November 4, 2012

Online Published: January 9, 2013

DOI : $10.5430 /$ jnep.v3n7p9

URL: http://dx.doi.org/10.5430/jnep.v3n7p9

\begin{abstract}
Critical thinking (CT) is a phenomenon of worldwide importance and is a desired outcome in higher and professional education. Development of CT is considered a primary responsibility of educators; however, educators find it challenging to foster learners' CT if their own understanding of CT skills and concepts is not well developed. Limited research is available on how multidisciplinary educators perceive and practice CT. The study aimed to identify perceptions and practices of CT among educators from the disciplines of nursing, medicine, and education in higher education in Karachi, Pakistan. A descriptive exploratory qualitative design was used where 12 purposefully selected educators from three disciplines participated. Semi structured interviews were conducted and content analysis was done. Although the findings revealed four major themes, the focus of this paper is limited to the theme of faculty perceptions. Faculty's perceptions of nature, acquisition, and application of critical thinking are multidimensional and although the educators were from various disciplines their perceptions of critical thinking were analogous. Thus combined efforts by all multidisciplinary educators in a higher education are needed to assist them to actualize their perceptions to promote CT practices in a classroom setting.
\end{abstract}

\section{Key words}

Perceptions, Critical thinking, Multidisciplinary educators

\section{Background}

Critical thinking (CT) is a desired outcome across the educational spectrum particularly in higher and professional education and a common goal that most faculty aspire to achieve ${ }^{[1-7]}$. It has been identified as an important attribute to be assessed and nurtured in higher education and professional programs ${ }^{[8-10]}$. Critical thinking can be developed through classroom and practical learning experiences ${ }^{[11,12]}$. Its development is considered a primary responsibility of educators $^{[13,14]}$. However, educators find it challenging to foster their students' CT if their own critical thinking skills are not well developed because they may not have learned CT in their educational programs or through continuing education $^{[15-17]}$. Educators need a clear and comprehensive understanding of CT and related concepts to foster it among 
students. Although most educators and scholars agree that CT is important, there appears to be a lack of agreement regarding its definitions amongst educators from various academic disciplines ${ }^{[10,18-20]}$.

A multitude of differing CT definitions have been provided by educators in academic and health disciplines ${ }^{[1,5,12,19,21,22]}$. These definitions are quite divergent because individuals have defined CT based on their own understanding, emphasizing different perspectives ${ }^{[4,20,23-25]}$. CT is viewed as a reasonable reflective thinking skill that focuses on deciding what to believe or do ${ }^{[26]}$. It is seen as a purposeful, self - regulatory judgment ${ }^{[27]}$ and an abstract skill that is difficult to measure ${ }^{[28]}$. CT is considered a meta cognitive activity that challenges previous assumptions ${ }^{[29]}$ as well as a composite of knowledge, attitudes, and application of skills ${ }^{[7]}$. Some suggests CT to be an interactive reflective reasoning process ${ }^{[30]}$ whereas others view it as higher order reasoning to reach a professional judgment ${ }^{[31]}$. Some relate to CT as a thinking process ${ }^{[13]}$, whereas others suggest that $\mathrm{CT}$ is a teaching learning process to achieve an outcome ${ }^{[7,32,33]}$.

Some researchers argue that the abundance of multifaceted definitions results in lack of clarity and creates confusion among practitioners in understanding what CT is and influences its application in teaching ${ }^{[4,22,30,34]}$. The need for an integrated, multi-perspective description of CT encompassing all its components namely: skills, attitude, knowledge, and moral orientation are stressed ${ }^{[8,35]}$. Although attempts to develop a common consensus for a definition of CT has been achieved through two Delphi reports ${ }^{[27,34]}$, some differences are evident between them as a result of the composition of expert panels involved in the study. Raymond and Profetto-McGrath in their study of nurse educators found that their perspectives differed from those in other disciplines and they preferred to describe CT rather than define it ${ }^{[36]}$. Likewise, Gordon contends that nurse educators have a perception of CT that is different from scholars in other disciplines, thus suggesting that practice disciplines may perceive CT differently from educators in non - practice disciplines ${ }^{[1]}$.

In addition, the term CT has also been used interchangeably with terms such as problem solving, decision making, scientific process, clinical reasoning, nursing process, and evidence - based practice ${ }^{[30]}$. This lack of clear boundaries between CT and related terms further impedes the understanding and communication of what CT is and how it can best be taught and assessed in learners. Furthermore, there is lack of clarity in terms of whether CT is discipline specific or a universal entity that spans across many disciplines. Twibell et al. assert that CT is context bound and is learned in a social process ${ }^{[20]}$. Whereas, Stone et al. argue that certain CT skills and dispositions bridge many disciplines ${ }^{[37]}$. Similarly, Gonczi suggests that CT is a transferable attribute that is not limited to one discipline or setting ${ }^{[38]}$. Likewise, Wang, Woo, and Zhao (2009) affirm that skills associated with CT could be learned independently of specific subjects and can be transferred from one domain to another ${ }^{[39]}$. However, Maudsley and Strivens question whether CT is similarly important in higher education and health care practice, and whether educators and clinicians mean the same thing by $\mathrm{CT}^{[40]}$. Thus, further exploration is required to understand CT from a multidisciplinary perspective in order to develop further insights about subject specificity or generality and transferability of $\mathrm{CT}^{[1]}$.

Given the importance of CT in practice disciplines and the influence of teachers' practices in developing students' CT, it is essential to explore various educators' perceptions and practices of CT in the local context. Moreover, with the growing trend of multi -disciplinary teaching in universities, it is vital to concurrently explore the perceptions and practices of CT among educators from a variety of disciplines in order to develop a more holistic insight into the phenomenon. The need to seek a discipline - specific definition when CT is considered a meta cognitive process unrelated to a particular knowledge domain is questioned ${ }^{[17]}$. Likewise, educators are challenged to move away from focusing on a consensus in CT definition as CT requires a thorough explanation of its components, features, phases, and characteristics and so it should not be reduced to a singular definition ${ }^{[24]}$. While Seldomridge and Walsh propose that an opportunistic need exists to conduct cross - discipline research among health professionals and other practice discipline in order to broaden the scope and meaning of the CT phenomenon ${ }^{[41]}$.

Teachers who possess an understanding of what it means to think critically and how to engage students in thinking critically promote CT, whereas those who have not mastered CT themselves, cannot develop this form of thinking in their 
students because they do not know how to think critically and cannot be expected to teach their students to do so ${ }^{[42]}$. While the literature indicates that most teachers believe that developing CT in their students is imperative ${ }^{[17,43-45]}$, few know what CT is, and how it should be taught in the classroom ${ }^{[4]}$. It is, therefore, important to ascertain from educators of different disciplines what their understanding of CT is, in order to determine a basis from which one can proceed on how to promote it in learners.

In Pakistan the focus of education for students remains on rote learning rather than acquiring critical thinking skills, and for teachers as the givers of knowledge rather than as facilitators for students to develop their knowledge ${ }^{[2,46-49]}$. While awareness exists amongst teachers regarding the need for a paradigm shift from a teacher - centered approach to student centered learning ${ }^{[22,45]}$, this has not yet been achieved in Pakistan ${ }^{[46,47]}$. Several studies in higher education have explored CT definitions, its measurement, assessment of students' and educators' CT, and teaching strategies which promote CT. There are a limited number of research reports about CT in Pakistan and these have focused on the science and social studies curricula at the school level, and on school and college teachers of undergraduate programs ${ }^{[5,47]}$. However, no published research was found on how CT is perceived and practiced by educators in higher education in Pakistan.

In contrast, few western research studies exist which have explored the perceptions of CT among education teachers ${ }^{\text {[13] }}$ and nurse educators ${ }^{[1]}$, and compared the data with non - nurse scholars who had been study participants of an earlier research ${ }^{[27]}$. Gordon's findings reveal that nurse scholars differ in their perceptions about CT and suggest that nurse educators' CT dispositions are different because of the multifaceted nature of their profession ${ }^{[1]}$. Although considerable information exists regarding the definitions and the strategies for promoting CT in western countries, limited comparable information exists within the South Asian contexts in similar fields. Moreover, exploration of perceptions and practices of CT understanding among multidisciplinary educators, using a qualitative approach, has not been found in the literature.

Additionally, no international published research could be found that has explored perceptions of CT among educators from the nursing, medicine, and education disciplines to identify differences and similarities amongst them. Thus, it is logical to first explore the perceptions of CT of educators from different disciplines in Pakistan and understand CT in the Pakistani context, in order to develop strategies and expect educators to facilitate CT in learners. Although a few studies have explored perceptions of CT specific to nurse educators and college teachers in western countries, comparable information from a South Asian context is limited and no research has been done to explore perceptions of CT among educators from different disciplines.

With the trend to provide interdisciplinary teaching in universities in Pakistan, there is a need to explore the perceptions and practices of CT from the perspective of university educators in a variety of disciplines such as nursing, medicine and education. Such interdisciplinary exploration of CT understanding has not been reported in the literature and, therefore, it has been selected as the focus of this research study. The knowledge of educators' perceptions and practices regarding CT from multiple disciplines will assist in knowing how the CT culture is understood within a South Asian context. The study aimed to identify how CT is perceived and practiced among educators from the three practice discipline in order to conceptualize CT from a multidisciplinary eastern perspective.

\section{Study purpose}

The purpose of this study was to explore perceptions and practices of CT among educators from the disciplines of nursing, medicine, and education in higher education in Karachi, Pakistan. It was also the purpose of this study to identify the differences and similarities in the educators' perceptions and practices of CT. Specifically, the study aimed to answer the following questions:

- What are the perceptions of critical thinking among educators from the disciplines of nursing, medicine, and education in university settings? 
- What are the differences and similarities in the perceptions of CT among educators from the three disciplines?

\section{Methods}

\subsection{Study design and participants}

Using a qualitative approach, a descriptive exploratory design was used to explore the perceptions and practices of critical thinking amongst the faculty of nursing, medicine, and education disciplines. For each discipline, a private and a public university were chosen to create a heterogeneous purposive sample of 12 educators. The inclusion criteria constituted of faculty members who were currently employed at any university in Karachi belonging to the fields of nursing, medicine, or education, and who had current teaching experience for more than 5 years, and held a senior instructor rank or above. Any faculty member of foreign nationality with temporary work tenure, or faculty who had not been teaching regularly for at least one year or assigned only administrative and management duties were excluded.

\subsection{Ethical considerations}

The approval of the institutional ethics review board was sought to conduct the study. Administrative approval from the head of each university from where the participants were invited and selected was also sought. Informed written consent was obtained from each participant who agreed to participate in the study. The identity of the participants and their institutions was protected by assigning codes for institutions and pseudonyms for participants. The participants had the right to refuse and withdraw from the study at any time.

\subsection{Data collection}

Data was collected through semi structured interviews to elicit teachers' perceptions, experiences, opinions and feelings about CT. An interview guide comprised of open ended questions was used to guide the interviews (see Appendix A). Clarifying and elaborating probes were used to facilitate discussion and guide the interview process ${ }^{[50]}$. Each interview was approximately 45-60 minutes long. It was conducted bilingually in English and Urdu as per the participant's comfort and was recorded using an ICD digital recorder. Taped interview data was transferred to digital voice editor files for transcription by a transcriptionist who had command of the English and Urdu languages. The accuracy of the transcriptions was verified where needed. Safety of data was assured by keeping the hard data in a locked cabinet. The soft copies of the data folder were password protected in the researcher's personal computer.

\subsection{Data analysis}

Content analysis in a qualitative study is considered a spiral, iterative, and interpretative process ${ }^{[50-53]}$, thus, while the data was collected through interviews, constant review and reading of the data transcripts was simultaneously done to develop a deeper understanding of findings and to discover additional questions that needed to be asked or clarified from the participants. Content analysis involves reading through the data to obtain a general sense of the whole before breaking it into parts. It aims to inductively reduce data into smaller meaningful segments or codes and then categorize them to represent the data ${ }^{[50,51]}$ and understand its meaning. The collated mega transcripts were read several times to extract a sense of what the text data said or implied while thinking about the organization of the data. The summative approach for content analysis ${ }^{[54]}$ assisted in analyzing and interpreting meanings from the manifest and latent text data. Then, identification of certain keywords or content labels from the text data was done. Writing memos in the margins of transcripts helped in this initial process to obtain a sense of the data and to jot ideas and phrases that came to mind while reading the database.

Coding was done by identifying the text segments, placing a bracket around them, highlighting them with a different color marker, and assigning a label, word, or phrase to them that gave meaning to the segment. Coding assisted in the clustering of similar data into categories which subsequently condensed into a theme. The codes were written in the margins 
alongside the mega transcripts and were then drawn in a map or schema to visually examine them for overlap and redundancy. This assisted in collapsing the codes into categories and themes. The themes were layered and interrelated to display a holistic visual sequence of the phenomenon. Thematic analysis led to conclusions and assertions from the data. Saturation was achieved when no new data provided any additional codes categories or themes. Final conclusions were not drawn until all the data had been collected, indexed, and analyzed, ensuring that these conclusions were held with openness and skepticism.

\section{Findings}

\subsection{Demographic profile of the study participants}

The study sample comprised of 12 participants; seven males and five females. Their ages ranged between 30 and 52 years, with a median of 39 years. Seven participants had either a doctorate degree or were pursuing it, whereas others had a master's degree in their field. The participants belonged to four universities in Karachi, Pakistan; one being in the private sector and three in the public sector. The participants were from the medicine, nursing, and education disciplines. With regard to their academic titles, half of the participants were serving as senior instructors while the others were working as assistant professors or professors. Their teaching experience ranged from 5.5 years to 23 years with a median of 9 years. Six teachers had the experience of teaching students from other disciplines, as well as teaching students in their own discipline.

\subsection{Perceptions of CT}

\section{Theme: Multidimensionality of CT}

The participants' interview data related to perception of CT revealed the theme of multidimensionality of CT. When the participants were asked to describe their understanding of what is CT to them, its nature, origin, and its importance, they took a few moments to collect their thoughts before answering. The participants used different descriptions and phrases in Urdu and English to present their understanding of CT. The 'multidimensionality' theme was identified from in vivo codes when an educator stated, "CT has no boundaries...it is not uni-dimensional, it is a multidimensional phenomenon" (06-ET). The theme of multidimensionality was also evident in the narratives of the respondents in terms of diverse nature, acquisition and application of CT. Thus, in the next section, the participants' responses are presented here within three categories under the multidimensionality theme; nature, application and acquisition of CT (see Figure 1).

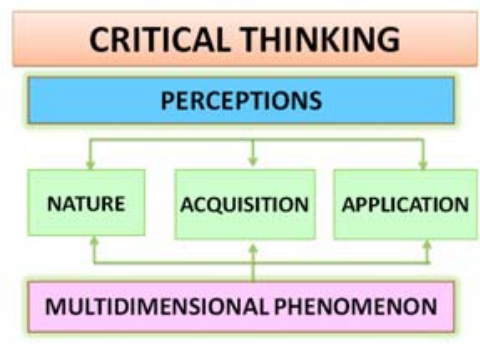

Figure 1. Theme and the categories

To indicate the study participants in general, the words participants, faculty, and teachers have been used interchangeably, whereas, in the accompanying quotes, the initials of MT, NT, and ET are used alongside a serial number to indicate whether the participant is from medicine, nursing, or education. In addition, some quotes have been retained in the Urdu language to enable appreciation of the richness of the participants' true expressions; however, the translation of these quotes into English is provided in brackets for those who do not understand Urdu. 
Category 1: Nature of CT. This category presents findings about the nature of CT. The participants from all disciplines shared diverse descriptions indicating CT as an art, a cognitive skill, a reflective process, an outcome, a behaviour, an approach and an attitude (see Figure 2). Thus the nature of CT is described in three subcategories: 1) an art, skill, process and outcome, 2) an attitude, behaviour and approach, and 3) terms associated with CT.

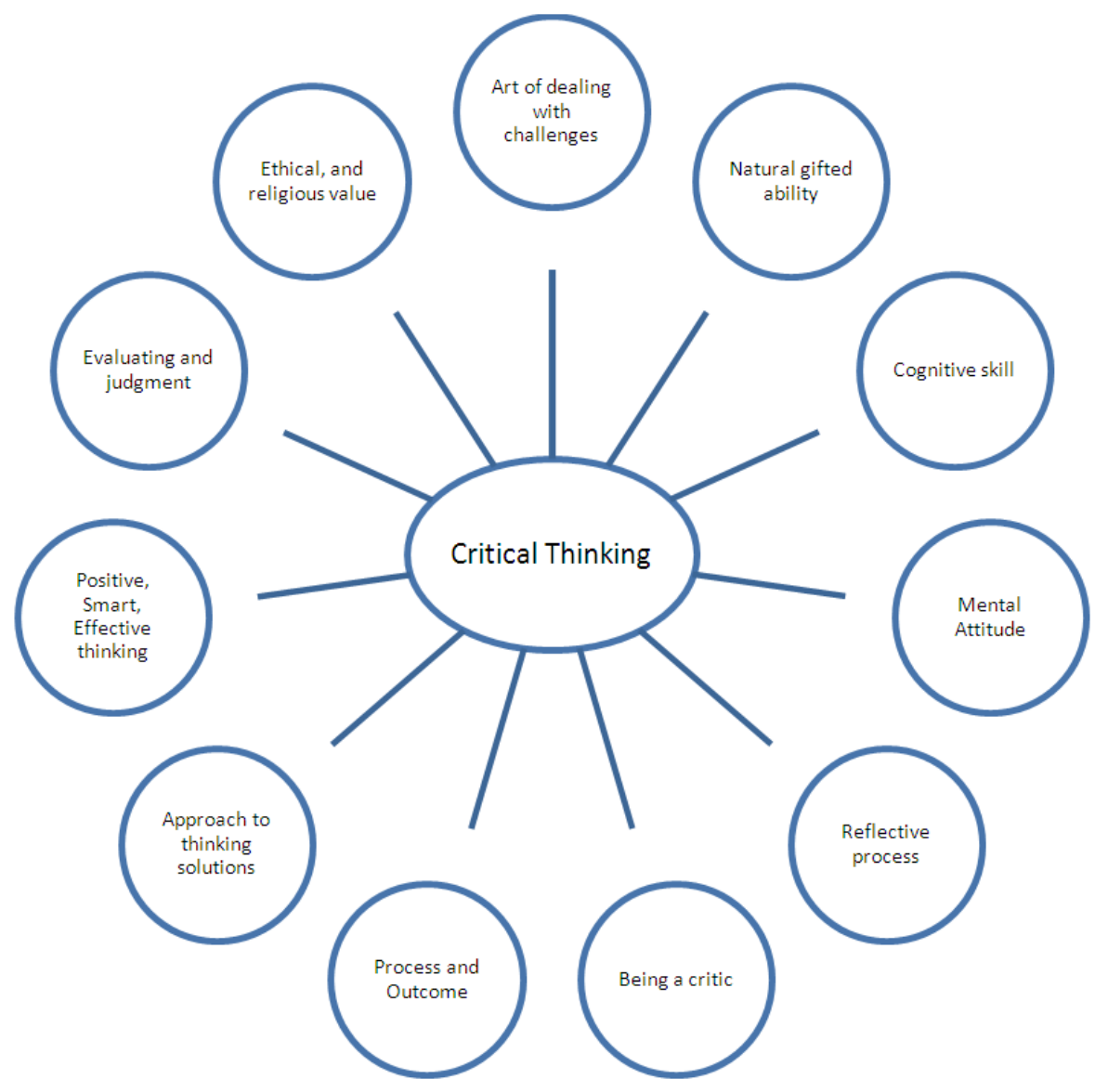

Figure 2. Multidimensionality in the nature of Critical Thinking

Sub category 1: CT as an art, skill, process, or an outcome. Several participants viewed CT as an art of deeper thinking, a cognitive skill, a process of logical reasoning, knowledge construction, rationalization, and application in certain contexts. For all of them, CT was a step beyond mere thinking. One participant referred to CT as, "smart thinking... in a timely manner... looking from a fresh lens for a different perspective" (04-NT). Another said it is "Gor o fiqar karna [deeper thinking]" (05-NT), while one faculty explicated that, "CT is an intellectual rationalization and reasoning ability and is one step ahead in thinking... it is deeper thinking" (08-NT). Likewise, one participant said, "When you go deep and carefully analyze something... you require evidence based science .... and use of formal or informal tools to go into the depth of a subject" (09-MT). While another participant affirming that CT is a cognitive skill of thinking more deeply about the issue, and pointed out that, "CT provokes one thinking; it may not always give answers but may lead to more questions and hence CT develops insight about the issue” (07-ET).

One faculty asserted that CT is "a logical step- wise approach to think on thinking” (03-NT), which was further illustrated by another teacher who said, "If I think why I am thinking, what I am thinking....and the consequences and background of that thought, it gives an exterior dimension, and becomes thinking on thinking... critical thinking” (06-ET). To elaborate the complexity of CT as a cognitive process, a faculty member stated that "CT is a kind of process for conducting an 
assessment of the situation, forming hypothesis, and analyzing by relating own knowledge and knowledge gained from others to take actions accordingly" (05-NT). Another faculty viewed the intricacies of this complex process as "Kisi bhi masley ke un pehluon ko ujagar karna, jo bazahir nazar nahi aatey hai aur aik tanqeedi nigah se uska jaiza lena or us ke baad uska hal talash karna”. He tried to explain the same thought in English as well:

Whenever you come across a situation, you should reason it out, and think about the factors, forces, reasons, and determinants of the situation, and should analyze it from an insider's perspective, why this happened, what are the reasons behind it and how we reached to this situation ... then think of the most possible, doable solutions. (MT-10)

In addition to being a cognitive, purposeful, step by step, logical reasoning process, some participants also mentioned that CT is a reflective process that can be used for self reflection, critique, and appraisal of others. They used various Urdu terms to describe CT as a critique process. The words used were: "Tanqeedi Jayza” [critical review] "Tanqeedi Soch" [critical thought] "Tanqeedi Nigahen” [critical eye] "Shatir Nighaen” [sharp vision]. The most commonly used term was tanqeedi that refers to criticizing or critically appraising something significant. Similarly, different English terms to describe a reflective thinker, such as reflexivity, scrutinizing, pondering, questioning, analyzing, and clarifying, were also used by the study participants.

The participants also shared that CT does not only mean criticizing others but also includes critical self reflection and questioning oneself, own assumptions and biases. One teacher pointed out that the "word critical is an adjective, [that] entails awareness and consciousness to scrutinize own or others' thinking process” (06-ET). He explained that when one critique any event, statement, there is an ideal or better possibility, "ke aisa hona chaiye" [it should be like this], so reflexivity and imagination are also part of critical thinking.

Another teacher expounded that asking oneself and others, why, how, and what type questions means you are doing CT. She explained, "We all think ... all the time, but when you ask the WH questions, then that makes it critical thinking, so you are looking on not just what's happening, but reflecting on all other aspects of it” (08-NT). A faculty shared that CT is, "one's ability to question, reflect, and re-examine our own thoughts...continuously to improve quality of outcomes...it is an Ahha moment" (07-ET). To express the ongoing nature of CT, another teacher said that, "a critical thinker never stops thinking but keeps on reflecting, what is going on, what went well, what are the outcomes, what can be done next time, and how can it be done in a better way" (05-NT).

In addition to being viewed as a cognitive and reflective process, some participants considered CT as an outcome and suggested that it can be a means to an end or an end in itself. One participant stated, "CT is certainly an outcome, as a teacher is working with the students for a whole year and the goal is to get students to be critical thinkers at the end of that year" (07-ET). Likewise, another participant clarified that CT is both, an outcome and a process, depending on its focus, saying, "it is all in different contexts, it is certainly a process but it is also an outcome" (06-ET). Similarly, another faculty explained how CT is a bit of process and outcome both, depending on the stage of educational journey. She explained, "If you are teaching, it becomes a process, but if you are looking at a graduate student [that is a critical thinker], than it's more of an outcome” (08-NT).

Sub category 2: CT as an attitude, behavior, and approach. In addition to viewing CT as an art, skill, a process and an outcome, some participants also described CT as an attitude, a behaviour, or an approach to deal with a situation. They used some characterizing phrases such as "thinking out of the box" "going beyond the obvious", "not accepting things at face value" and "giving a holistic picture in a wider context”. A teacher explained, "To be able to critically think and judge and react is a behaviour... to me it is a 'Modus Operandi' an approach to deal with the situation and to come to the resolution of a problem" (MT-10). The participant elaborated that the Latin term Modus Operandi refers to a tool or a modality that is employed by tactful people to reach a solution. Another faculty, expressing that CT is an alternative approach of thinking, and said, "mukhtalif zawiye se sochna or apney sochney samajhney ki salahiyat ko achey se buroikaar laana” [Thinking from a different angle or making good use of one’s thinking ability] (04-NT). 
Likewise, many participants also considered CT as a mental attitude and a positive habit of continuous thinking. One faculty described CT as a mindset or a learned personality trait that "a critical thinker uses for 24 hours a day" (05-NT). According to her, such an attitude instils curiosity, interest, creativity, presence of mind, and a readiness to go beyond boundaries, evidences, inhibitions, and limitations. Another teacher labelled CT as "achi musbat soch" [good positive thinking] and considered it a way of looking at both the positive and the negative side for gaining a holistic perspective" (11-ET). Yet another faculty member tried to differentiate between CT as an attitude and a habit and cautioned that "although CT is a socially learnt and constructed habit, the word habit has a negative connotation and has a burden of history, so it is more of an attitude rather a habit” (06- ET).

Sub category 3: Terms associated with CT. While sharing different CT perspectives, some participants also used some alternate terms or synonymous expressions or phrases interchangeably, such as problem solving, decision making, creative thinking, nursing process, and evidence based practice to describe CT (see Figure 3). However, after probing, these teachers were able to clarify their perceptions and differentiate these associated terms from CT.

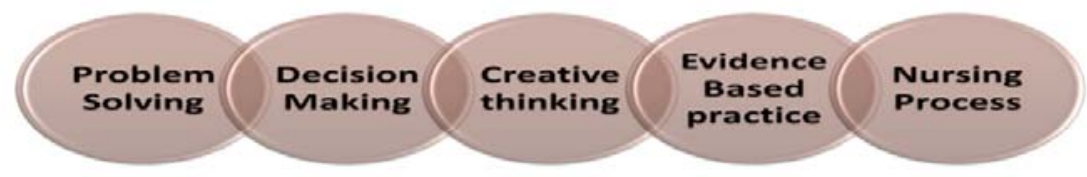

Figure 3. Terms associated with critical thinking

With regard to differentiating problem solving(PS) from CT, one faculty stated that "PS is superficial, spontaneous, and limited to problems, whereas CT is a complex, logical, and systematic approach towards looking at problems, situations, challenges as well as solutions" (10-MT). Similarly another faculty viewed CT as a continuous process, unlike PS, as reflected in this quote: "CT not only means to assess the situation and solve the problem, but once you have done that, you reassess again and look at it from a different level” (05-NT). These two faculty members seem to imply that PS is limited and focused and CT is a complex, systematic, ongoing reflective process. On the contrary, two other teachers maintained that PS and CT are interlinked because learning to solve a problem systematically promotes CT, which is the underpinning of a problem- based curriculum. Similarly, the term, decision making (DM) was also explained in relation to CT. A faculty member stated that for effective DM, CT is important but one may make decisions without CT.

Reflecting on the association between CT and creative thinking, one faculty asserted that, "creativity is a major attribute of a critical thinker, those who are creative and innovative are better at critical thinking. Thus for being a critical thinker, creativity, curiosity, and inquisitiveness are needed" (04 - NT). Another faculty addressed the similarity and differences of the nursing process (NP) with CT. To her "both the processes entailed assessment, hypothesis, analysis, and solution for a problem, but the scope of NP is narrow, limited to a patient, family, and community, whereas CT has a broader scope and application" (05-NT). Likewise, one faculty explained that evidence based practice (EBP) is different from CT because "EBP needs solid evidence to prove a point of view but through CT, you may have a hypothesis but you may not always prove it” (09-MT).

Thus it was noted that though participants from different disciplines expressed variety of perceptions related to nature of CT there were no specific differences between disciplines. Some of the participants associated CT with terms such as problem solving, decision making, creative thinking, nursing process, and evidence based practice. An analysis of the above excerpts reveals that although several terms were used interchangeably by the participants to denote CT, upon reflection, they were able to differentiate CT from its associated terms. Moreover, it is important to note that the use of these terms appears to be discipline specific. For example, the term PS was used more by teachers in the medical college and the term nursing process was used by the nursing faculty. 
Category 2: Application of CT. The second category describes findings about the importance and applicability of CT. The participant's narratives indicated that, although CT was, universally important for all fields, the application of CT seemed more demanding in some disciplines than others. Teachers from all disciplines verbalized that CT is a universal human phenomenon that is important and applicable across disciplines. A medical teacher maintained that "everyone should know how to think in critical way and analyze what is important for their profession” (02-MT). A nursing faculty also revealed that, regardless of the discipline, CT is important for all educators and asserted that "CT is needed to make decisions related to student learning, planning strategies, and developing their mind and thinking” (04-NT). Concurrently, an education faculty also explained that:

The method for teaching CT is the same for all disciplines, but the matter which we teach is different according to the discipline... and the method through which we judge our teaching is based on the context and the knowledge of the discipline (12-ET).

This participant implied that the principles and strategies for promoting CT may be the same in each discipline, but the knowledge, content, and context for CT is different and discipline specific. To clarify the significance of CT in different subjects, another education faculty stated, "CT is needed more in some disciplines than others as some subjects, like social studies, lend themselves more to CT, unlike mathematics" (07-ET). Likewise, another faculty expressed that, when it comes to professional services, "the importance of CT becomes more imperative in health care fields than in the education field, as nurses and doctors are in charge of human life" (06-ET). Concurrently, another teacher also reinforced that CT is more important in medicine and nursing as "they are dealing with human beings and making emergency kind of decision, [whereas] we are building the future teachers mind, cultivating in them a kind of open mindedness to make informed decisions" (07-ET). Unlike the faculty in education, the nursing teachers had slightly different views. One of them remarked that, "CT is equally important to the nursing as well as the education discipline” (08-NT), whereas another stated that "CT is more important for a nurse than a doctor, because a doctor comes, prescribes and goes, but nurses take care of the patient for 24 hours...assess the situation and take action accordingly" (03-NT). Thus, although most participants believed that CT is universally applicable and equally important in all disciplines, some participants thought that the use of $\mathrm{CT}$ is more crucial in some context than in others.

Category 3: Acquisition of CT. The third category describes the faculty's multidimensional views about the origin and the development of CT. The participants' narratives illustrated that CT is a natural innate ability as well as an acquired art. Moreover, for some of them CT was an ancient phenomenon as depicted in the religious and ethical values. Two of the medical teachers considered CT to be an innate ability of human beings that people use in varying degrees. As one of them explained that CT is a "natural gift from God who made humans ashraful makhlooqat [superior] among all creatures, to do thinking ... but if this ability to explore the depths and secrets of the universe is not used, then it is an individual's fault" (10-MT). Congruent with this belief, another faculty expressed that CT is further developed or suppressed by environmental, societal, parental, peer and schooling experiences:

Some children ask outstanding questions in the class....[and]you wonder how they thought of such questions, and how we can satisfy them. CT is a God gifted thing, but in certain environments, we suppress the ability and in some cases, parents or other people polish them and give children confidence; so they become critical thinkers, as they had good environment (01-MT).

Contrary to the above views, two teachers felt that CT is a learned art which has no natural or genetic origin, as it is difficult to assess whether a child possesses CT at birth. One teacher asserted that, "CT is a socially learnt art, constructed from experiences, home environment, school, university, and exposure to role models” (06-ET), whereas another teacher explained that CT is an art that is developed in early childhood: 
We are not born critical thinkers... It's a skill which is cultivated in the home for example, in the family, exposing children to books, I mean parents asking questions to the children that, what did you do in the school and ... things like that, so it is fostered at an early age (07-ET).

Thus, most study participants, regardless of their discipline, believed that CT is not purely a natural skill, but a combination of innate ability complemented in the home and school environment, through role modelling by parents and teachers. A medical faculty summarized the mixed origin of CT and said, "I think actual critical thinkers are very smart, they may be born critical thinkers, but, of course, they also have an enabling environment, a background, an interest, as they have this approach while looking at all aspects of life issues" (10-MT).

In addition, some participants pointed out that certain CT values such as honesty, curiosity, inquiry, search for knowledge, and self-reflection have originated from religious teachings, and are grounded in moral and ethical perspectives. A teacher contemplated that "Christianity supports seeking answers, rationalization, and gives liberty for questioning things at face value" (08-NT). Another teacher affirmed that "CT is not a new, modern, or emerging concept but is the oldest way to analyze and judge somebody according to Islamic teachings” (02-MT). Likewise, one faculty pointed out that Islam reinforces CT values:

Islam is a complete zaabta-e-hayaat [way of life]...Our religion reinforces values of reading, analyzing, and use of logic. The Holy Book Quran, God's Prophets and Imams [descendants] all endorsed these values. Imam Abu Hanifa used mantaq [logic] for explaining to people. Islam teaches us ghuftaghu thehr ka karo [speak calmly using pauses and silence], pehley tolo phir bolo [first think and then speak]. Reading and speaking well are important values for critical thinkers. Sahaba -e- Karaam,[companions of Prophets] are famous for their quiet reflection. Attitudes like reflection before action, pausing before speaking, and ethical values like honesty, fairness, and trustworthiness are supported by Islam (03-NT).

Similarly, another faculty stated that Islam supports attitudes of discovery and exploration:

Allah [God] has kept many things in secret. He says, “tum ghor kyon nahi kartey” [why don’t you think deeply] meaning go and discover this universe, ponder over the secrets in it. He has endowed us with skills to explore universe, which is not possible without critical thinking. Man is on the moon, in the depth of the oceans, is going to create life on other planets, is able to fly faster than time, this is all possible due to critical thinking (10-MT).

Thus, the study participants had multidimensional perspectives about the acquisition of CT; of it being an innate God gifted natural ability; and a socially constructed and learnt art as well as an ethical and religious value endorsed by Christianity and Islam.

\section{Discussion}

The current study identified the perceptions of CT from the faculty of nursing, medicine, and education disciplines and identified similarities and differences among disciplines. The diversity of CT perceptions evident in the current literature ${ }^{[4,20,21,23-25,36]}$ is explained by this study findings which suggests that CT is a multidimensional phenomenon in terms of its nature, acquisition and application. Most participants in this study did not define CT but described it as a skill, an art, a cognitive process, a reflective process, an outcome, an approach, an attitude, and a ethical and religious value. They used different terms, phrases, and expressions which is similar to the findings in the literature ${ }^{[1,36,55]}$. However, a comparable list of Urdu vocabulary for describing CT were identified through this study such as (i.e. Gor o fiqr karna' [thinking and reflection], Mukhtalif zawiye se sochna” [thinking from a different perspective], Musbat Soch [positive thinking] and tanqeedi soch, [critical thought]) that could be useful in teaching native students terms in Urdu language to describe CT. 
Many study participants while explaining the term "critical” in Urdu, used the word tanqeedi which refers to critique. This draws attention to the fact that the faculty had a biased understanding of the word critical and thus they found it difficult to describe CT as thinking beyond evaluation and judgment when it came to their native language. These findings are congruent to a study which state that the English term 'critical' wrongly identifies the term critical as a critique or an evaluative judgment against a given criteria, and not as an effective thought ${ }^{[56]}$. Unfortunately, the term critical is a misnomer and is limitedly used for critique and criticizing, although CT does not solely mean criticizing, scrutinizing, evaluating or questioning in a negative sense ${ }^{[15]}$.

Studies suggest that in order to reflect the true meaning of critical as important and to represent the holistic perspective of CT, the difference between critical and effective thinking must be clarified ${ }^{[42,56]}$. The authors of these studies argue that the notion of good, smart, or effective thinking is much better as these terms accurately reflect what CT entails; that is, analytical thinking, engagement, interrogation of knowledge, pursuing self-directed learning, and questioning. Interestingly, some participants in the current study also expressed terms such as smart thinking, effective thinking, and rational thinking besides critical thinking, which supports that some study participants' thinking also goes beyond critique.

The narratives of all participants reveal that for them, CT is a multidimensional phenomenon which has diversity in its nature, application, and acquisition. Although the multi dimensionality of CT has been identified in the literature ${ }^{[57]}$ with regard to its definitions, the findings of the current study expand the thinking about multidimensionality as to its nature, acquisition and application, thus reflecting a holistic view of CT. Similar to the findings in the existing literature ${ }^{[13,24,44,58-60]}$, most of the study participants viewed CT as a complex, cognitive process for analytical thinking and

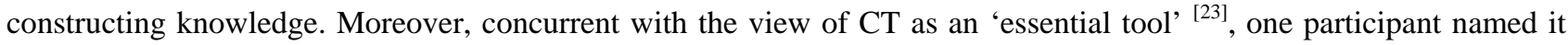
'Modus Operandi'; a tool which helps individuals to intelligently deal with a situation and reach a resolution. For the participants of this study, CT was also a reflective process which can be private and public and entails sufficient consciousness to scrutinize the thinking process. This understanding is similar to others ${ }^{[13,14,24,30,61]}$, who identified CT as appraising, evaluating, questioning self, and challenging one's own assumptions as well as those of others. Likewise, the findings of this study also revealed that participants considered CT to have a reflective skepticism and imaginative dimensions which is already identified in literature ${ }^{[59]}$.

In line with the views of various authors ${ }^{[7,13,21,32,33]}$ of CT as a process, an outcome or both, the current study participants also affirmed that CT is a generic term that can mean process or outcome or both as it is dependent on the context. They suggested that process is a course of action and outcome is its consequence, thus outcomes are not independent of process. Nonetheless, it is important to note that when the participants viewed CT as a process, its application was suggested to be universal across disciplines as it entails general skills and attitudes, whereas when it was referred to as an outcome, it was weighed against a specific discipline or a subject context which is consistent to literature ${ }^{[6]}$.

The participants of this study expressed that CT is a mental art, an attitude or a habit of doing things skillfully which is similar to CT dispositions ${ }^{[55]}$ and habits of mind ${ }^{[14]}$. A participant in the current study explicated that instead of viewing CT as a habit, it should be considered an attitude as the former term has a negative connotation. In line with several authors $^{[1,30,35,62]}$, the participants interchangeably used various terms, such as evidence based practice, problem solving, and nursing process to describe CT. However, the participants were able to redefine the relationship of these terms with CT when the researcher dialogued to clarify meanings of these associated terms. This helped the participants of this study to operationalize, challenge, and externalize their own tacit knowledge and draw new conclusions for future reference as suggested ${ }^{[13]}$ in another study.

Studies assert that nurse educators, more than non nurse experts, view research, problem solving, decision making, and planning as $\mathrm{CT}^{[1,21]}$. Unlike their assertion, the findings of this study reveal that educators from all disciplines used some associated terms, albeit specific to their discipline. The education faculty used terms such as good thinking, effective thinking and positive thinking and related these with CT. The nursing faculty associated the nursing process and evidence 
based practice with CT as these are the most commonly used concepts for them. Likewise, the medical faculty frequently related CT to problem solving, which may be due to the fact that all study participants from medicine were using a problem based approach in their curriculum, which is believed to promote $\mathrm{CT}^{[9,39]}$.

Consistent with several authors ${ }^{[6,19,35-37,39]}$ the study participants expressed that CT is important for any discipline and makes one academically as well as socially successful. The participants affirmed that although the principles and strategies for promoting CT remain the same for all disciplines the context, content, and the assessment of learners can be different. This finding clarifies the issue of specificity and universality of CT phenomenon and supports other research studies that within a specific epistemological subject, the perception of CT varies from field to field ${ }^{[6,37,39]}$. With regard to the relevance of CT to a specific subject, the participants suggested that some subjects such as social studies lend themselves more to CT than others, like mathematics, implying that CT is a subject specific skill; as asserted by others ${ }^{[6,37,39]}$. Additionally, the participants of this study supported earlier research ${ }^{[42]}$ that recognized CT as a generic ability required in all disciplines.

Contrary to the existing literature, that supports the importance of CT to nursing, medicine, and education, the education faculty in this study pointed out that CT is more applicable to health related disciplines. They rationalized that the need for CT is more acute and vital in health care fields than education because nurses and doctors deal with life and death situations, whereas, education deals with developing students' mind in the classroom. This difference in the finding may be attributed to the fact that the education faculty had gained insight into the work of doctors and nurses through personal or family's experiences in hospitals.

Study participants viewed the acquisition of CT as a God gifted ability provided to human beings and it is enhanced or suppressed by human and environmental factors and early development. This finding coincides with report ${ }^{[44]}$ that thinking is a natural process which, if left on its own, can become biased and distorted; therefore, it needs to be nurtured. The study participants also indicate that CT is an innate quality present in human beings and its development is dependent on various environmental factors such as parents and teachers, the learning environment, the social context of learning, and the instructor's teaching style. The study participants also pointed out that when CT is not properly developed in early childhood by parents, teachers, and basic schooling experiences, its consequences are faced later in higher education settings when students are not able to demonstrate CT behaviours as suggested ${ }^{[63]}$. Hence, it is important for teachers to determine students' ability to think critically followed by a development plan to develop or enhance it.

The findings of this study indicate that the concept of CT exists in the religious, ethical, and moral teachings of Islam and Christianity, as the participants quoted some Quranic ayaats [Holy Book excerpts], as detailed in the findings section. The participants mentioned that the Prophets, Imams (descendants of the Prophet) and Sahaba (companions of Prophet) demonstrated certain CT skills and values through role modelling. Restrained evidence about the religious and ethical origins and acquisition of CT abilities, attitudes, and skills are mentioned in a subdued manner by two studies ${ }^{[57,64]}$, who believe that CT may have a cultural, moral, judgmental, and ethical orientation. However, the connections of CT to moral and religious ethics were clearly externalized by the participants of the current study.

\section{Limitations of the study}

The possible limitations of the study were identified and added measures were taken to maintain the credibility and rigor of the study. 1) For maximizing sample variation, efforts were made to select participants with diverse educational background, age, gender, and teaching experience, as well as experience of teaching students from other disciplines, to represent greater variability in the sample. Maximization was further enriched by including faculty from both public and private sector universities, as major differences are found in the culture of a public and a private university in Pakistan. 2) For preventing the loss of information, and ensuring the reliability of translated data, that occurs when translation of narratives from one language to another is done ${ }^{[50,51]}$, the transcripts were reviewed closely and verified with the recorded 
data. Moreover, when it was felt that the translation was changing the meaning of the content, as some words in Urdu did not have the same meaning as in English, the Urdu phrases were kept as they were and the phrases were transliterated in the transcripts. In addition, the verification of the transcripts with the participants also helped in ensuring the accuracy of their accounts. Despite above measures taken to reduce study limitations, the study encountered time and expertise challenges that were beyond the control and scope of the novice researcher, such as applying higher levels of testing, analysis and specific mixed designs that are possible for a established researcher.

\section{Recommendations for future studies}

The study establishes a need to identify the perceptions of CT amongst faculty at an individual, organizational and national level, since perceptions influence educators' teaching practices. Teachers must give thoughtful consideration to their personal and organizational value beliefs that drive their teaching approaches, and commit themselves to promoting CT and active learning. There is a need to develop a shared philosophy of CT among the faculty of different disciplines, especially those who are working in large universities and are involved in multidisciplinary teaching. Because sharing expressions clarifies personal meanings, it is important to provide opportunities to faculty to participate in educational dialogue forums where they can share their perceptions of CT with other faculty who are not necessarily from their own discipline. More collaboration among the faculty of various disciplines must be encouraged to foster CT from a multidisciplinary perspective.

In addition, a quantitative study to validate the themes generated in this study through factor analysis will take the study results to a higher level of testing and enrich applicability of the research findings to a larger setting and population. Thus, when the identified factors that influence CT perceptions of educators are known, teachers training workshops and programs for faculty development to improve the CT knowledge and skills can be developed ${ }^{[65]}$.

\section{Acknowledgement}

Sincere appreciation to the study participants who willingly participated in the study and shared their valuable opinions and perceptions of the study phenomenon and sincere gratitude to University Graduate Program for funding this research endeavour.

\section{References}

[1] Gordon J. Congruency in defining critical thinking by nurse educators and non - nurse scholars. Jour of Nursing Education. 2000; 39: 340-351.

[2] Gul R, Cassum S, Ahmad A, Khan S, Saeed T, \& Parpio Y. Enhancement of critical thinking in curriculum design and delivery: A randomized controlled trial for educators. Procedia Social and Behavioral Sciences. 2010; 2: 3219-3225. http://dx.doi.org/10.1016/j.sbspro.2010.03.491

[3] Kalb A. Core competencies of Nurse Educators: Inspiring excellence in nurse educator practice. Nurs Educ Perspectives. 2008; 29: 217-19. PMid:18770950

[4] Mundy K, \& Denham S A. Nurse educators - still challenged by critical thinking. Teaching and Learning in Nursing Education. 2008; 3:94-99. http://dx.doi.org/10.1016/j.teln.2008.02.007

[5] Ovais R. Facilitating teachers' understanding and teaching of critical thinking as a way to develop students' political literacy. 2008. Available from: www.aku.edu/ied/confernce2008doc/Papers

[6] Renaud R D, \& Murray HG. A comparison of a subject - specific and a general measure of critical thinking. Thinking Skills and Creativity. 2008; 3: 85-93. http://dx.doi.org/10.1016/j.tsc.2008.03.005

[7] Staib S. Teaching and measuring critical thinking. Jour of Nurs Edu. 2003; 42: 498 - 508. PMid:14626388

[8] Ku KYL. Assessing students' critical thinking performance:Urging formeasurements using multi - response format. Thinking skills and Creativity. 2009; 4:70- 76. http://dx.doi.org/10.1016/j.tsc.2009.02.001

[9] Profetto-McGrath J. Critical thinking and evidence-based practice. Jour of Profes Nurs. 2005; 21: 364-71. PMid:16311232 http://dx.doi.org/10.1016/j.profnurs.2005.10.002 
[10] Spencer C. Critical thinking in Nursing: Teaching to diverse groups. Teaching and Learning in Nursing. 2008 ; 3 : 87 - 89. http://dx.doi.org/10.1016/j.teln.2008.02.001

[11] Loving G L, \& Wilson J S. Infusing critical thinking into the nursing curriculum through faculty development. Nurse Educator. 2000; 25: 70 - 75. PMid:11052003 http://dx.doi.org/10.1097/00006223-200003000-00008

[12] Seymour B, Kinn S, \& Sutherland N. Valuing both critical and creative thinking in clinical practice: Narrowing the research-practice gap. Jour of Advanced Nursing. 2003; 42: 288-296. PMid:12680973 http://dx.doi.org/10.1046/j.1365-2648.2003.02618.x

[13] Choy S C, \& Cheah P K. Teacher Perceptions of Critical Thinking Among Students and its Influence on Higher Education. International Journal of Teaching and Learning in Higher Education. 2009; 20:198-206 Retrieved from http://www.isetl.org/ijtlhe/ISSN1812-9129.

[14] Rubenfeld M G, \& Scheffer B K. Critical thinking TACTICS for nurses. 2006. Boston: Jones \& Bartlett.

[15] Emir S. Education faculty students' critical thinking disposition according to academic achievement. Procedia Social and Behavioral Sciences. 2009; 1: 2466-9. http://dx.doi.org/10.1016/j.sbspro.2009.01.433

[16] Profetto-McGrath J, Smith K B, Hugo K, Patel A, \& Dussault B. Nurse educators' critical thinking dispositions and research utilization. Nurse Education in Practice. 2009; 9:199-208. PMid:18701349 http://dx.doi.org/10.1016/j.nepr.2008.06.003

[17] Zygmont D M, \& Schaeffer K M. Assessing the critical thinking skillsof faculty: What do the findings mean for nursing education? Nur Edu Perspectives. 2006; 27: 260 - 268. PMid:17036684

[18] Allen G D, Rubenfeld M G, \& Scheffer B K. Reliability of assessment of critical thinking. Journal of Professional Nursing. 2004; 20:15 - 22. PMid:15011189 http://dx.doi.org/10.1016/j.profnurs.2003.12.004

[19] Ozkan I. A path to critical thinking. Procedia Social and Behavioral Sciences 2010; 3:210 - 212. http://dx.doi.org/10.1016/j.sbspro.2010.07.034

[20] Twibell R, Ryan M, \& Hermiz M. Faculty perceptions of critical thinking in student clinical experiences. Jour of Nur Edu. 2005; 44: 71 - 79. PMid:15719714

[21] Fesler-Birch D M. Critical thinking and patient outcomes: A review. Nursing Outlook. 2005; 53:59-65. PMid:15858523 http://dx.doi.org/10.1016/j.outlook.2004.11.005

[22] Simpson E, \& Courtney M. Critical thinking in nursing education: Literature review. International Journal of Nursing Practice. 2002; 8: 89 - 98. PMid:11993582 http://dx.doi.org/10.1046/j.1440-172x.2002.00340.x

[23] Alazzi FK. Teachers’ perceptions of critical thinking: A study of Jordanian secondary school social studies teachers. The Social Studies. 2008; 243-248. http://dx.doi.org/10.3200/TSSS.99.6.243-248

[24] Riddell T. Critical assumptions: Thinking critically about critical thinking. Jour of Nur Edu 2007; 46: 121-126. PMid:17396551

[25] Walsh CM, \& Seldomridge L A. Measuring critical thinking: One step forward, one step back. Nurse Educator. 2006; 31:159-162. PMid:16855484 http://dx.doi.org/10.1097/00006223-200607000-00008

[26] Ennis, RH. A taxonomy of critical thinking dispositions and abilities. In Teaching thinking skills: Theory and practice. J. Baron \& R. Sternberg, eds. New York: Freeman. 2007; 9-26.

[27] Facione PA. Critical Thinking: A Statement of Expert Consensus for Purposes of Educational Assessment and Instruction. The Delphi report: Research Findings and recommendations 1997; Washington, DC: American Philosophical Association. .

[28] Adams M H, Whitlow J F, Stover L M, \& Johnson K W. Critical thinking as an educational outcome: An evaluation of current tools of measurement. Nurse Educator.1996; 21: 23-32. PMid:8788823 http://dx.doi.org/10.1097/00006223-199605000-00009

[29] Beeken JE, Dale ML, Enos MF, \& Yarbrough S. Teaching critical thinking skills to undergraduate nursing students. Nurse Educator. 1997; 22: 37-9. PMid:9197656 http://dx.doi.org/10.1097/00006223-199705000-00016

[30] Turner P. Critical thinking in nursing education and practice as defined in the literature. Nurs Edu Perspectives 2005;272-277.

[31] Seldomridge LA, \& Walsh CM. Measuring critical thinking in graduate education: What do we know? Nurse Educator. 2006; 31:132-137. PMid:16708038 http://dx.doi.org/10.1097/00006223-200605000-00011

[32] Alfaro-LeFevre R. Critical Thinking in Nursing, Philadelphia: Saunders,1995

[33] Ball AL, \& Garton BL. Modeling higher order thinking: The alignment between objectives, classroom discourse, and assessments. J Agricul Edu. 2005; 46:58-69. http://dx.doi.org/10.5032/jae.2005.02058

[34] Scheffer BK, \& Rubenfeld MG. A consensus statement on critical thinking in nursing. J Nurs Edu. 2000 ; 39 : $352-359$. PMid:11103973

[35] Daly WM. Critical thinking as an outcome of nursing education. What is it? Why is it important to nursing practice? J Adv Nurs. 1998; 28: 323-331. PMid:9725729 http://dx.doi.org/10.1046/j.1365-2648.1998.00783.x

[36] Raymond CL, \& Profetto-McGrath J. Nurse educators' critical thinking: Reflection and measurement. Nurse Edu in Practice. 2005; 5: 209-217. PMid:19038201 http://dx.doi.org/10.1016/j.nepr.2004.10.004

[37] Stone CA, Davidson LJ, Evans JL, \& Hansen MA. Validity evidence for using a general critical thinking test to measure nursing students’ critical thinking. Hol Nurs Prac. 2001; 15:65-74. PMid:12120497 
[38] Gonczi A. Competency-based assessment in the professions in Australia. Assessment in Education. 1994; 1: 27-44. http://dx.doi.org/10.1080/0969594940010103

[39] Wang Q, Woo HL, \& Zhao J. Investigating critical thinking and knowledge construction in an interactive learning environment. Interactive Learning Environments. 2009; 17:95- 104. http://dx.doi.org/10.1080/10494820701706320

[40] Maudsley G, \& Strivens J. Promoting professional knowledge, experiential learning and critical thinking for medical students. Medical Education. 2000; 34:535-544. PMid:10886636 http://dx.doi.org/10.1046/j.1365-2923.2000.00632.x

[41] Walsh CM, \& Seldomridge LA. Critical thinking: Back to square two. J Nur Education. 2000; 45:212-219.

[42] Pithers RT, \& Soden R. Critical thinking in Education: A review. Educ Research. 2000; 42: 237-249.

[43] Distler JW. Critical thinking and clinical competence: Results of the implementation of student - centered teaching strategies in an advanced practice nurse curriculum. Nurse Edu In Prac 2007; 7: 53-59. PMid:17689424 http://dx.doi.org/10.1016/j.nepr.2006.08.003

[44] Duron R, Limbach B, \& Waugh W. Critical Thinking Framework for any discipline. International J of Teach and Learn in Higher Educ. 2006; 17:160-166.

[45] Mangena A, \& Chabeli MM. Strategies to overcome obstacles in the facilitation of critical thinking in nursing education. Nurse Educ Today. 2005; 25: 291-298. PMid:15896414 http://dx.doi.org/10.1016/j.nedt.2005.01.012

[46] Davies L. \& Iqbal Z. Tensions in Teacher Training for School Effectiveness: The Case of Pakistan. School Effectiveness and School Improvement 1997; 8:254-266. http://dx.doi.org/10.1080/0924345970080205

[47] Dean B. Citizenship education in Pakistani schools: Problems and possibilities. International Journal of Citizenship and Teacher Education. 2005; 2: 35- 55.

[48] Khalid SM, \& Khan MF. Pakistan: The state of education. The Muslim World. 2006; 96:305-322. http://dx.doi.org/10.1080/0924345970080205

[49] Siddiqui, S. Rethinking Education in Pakistan. Perceptions, practices and possibilities. Karachi, Pakistan: Paramount, 2007.

[50] Creswell, JW. Educational Research: Planning, conducting and evaluating quantitative and qualitative research. (3rd ed.). New Jersey: Prentice Hall, 2008

[51] Polit, DF, \& Beck, CT. Nursing research: Generating and assessing evidence for nursing practice (8th ed.). Philadelphia: Lippincott Williams \& Wilkins, 2008.

[52] Miles, MB, \& Huberman, AM. Qualitative data analysis: A source book of new methods (2nd ed.). Thousand Oaks, CA: Sage, 1994.

[53] Speziale HJ, \& Carpenter RD. Qualitative research in nursing (3rd ed.). Philadelphia: Lippincott Williams \& Wilkins, 2003.

[54] Hsieh HF,\& Shannon SE. Three approaches to qualitative content analysis.Qualitative Health Research. 2005; 15: 1277-1288. PMid:16204405 http://dx.doi.org/10.1177/1049732305276687

[55] Facione PA, Facione NC, \& Giancarlo CAF. The motivation to think in working and learning. New Directions for Higher Education 1996; 96:67-79. http://dx.doi.org/10.1002/he.36919969608

[56] Papastephanou M, \& Angeli C. Critical Thinking Beyond Skill. Educational Philosophy and Theory. 2007; 39: 604-621. http://dx.doi.org/10.1111/j.1469-5812.2007.00311.x

[57] Hayes D. Critical thinking in undergraduate student nurses: Reflection and selective literature review. Malaysian J Nursing. 2010; 1: 4-7.

[58] Brookfield, SD. Developing Critical Thinkers: Challenging adults to explore alternative ways of thinking and acting. San Francisco: Jossey-Bass, 1987. PMid:3101787

[59] Jones SA, \& Brown LN. Critical thinking: impact on nursing education. J of Adv Nurs 1991; 16:529-533. PMid:1856371 http://dx.doi.org/10.1111/j.1365-2648.1991.tb01687.x

[60] O’Sullivan PS, Blevins-Stephens WL, Smith FM, \& Vaughan-Wrobel B. Addressing the National League for Nursing critical-thinking outcome. Nurse Educator. 1997; 22:23-29. PMid:9069939 http://dx.doi.org/10.1097/00006223-199701000-00008

[61] Dewey, J. How we think. New Delhi: Cosmo, 2006

[62] Worell JA, \& Profetto-McGrath J. Critical thinking as an outcome of context based learning among Post RN students: A literature review. Nurse Educ Today. 2007; 27: 420-426. PMid:16945453 http://dx.doi.org/10.1016/j.nedt.2006.07.004

[63] Croskerry P. Critical Thinking and Decision Making: Avoiding the perils of thin slicing. Annals of Emergency Medicine. 2006; 48: 720 - 722. PMid:17112936 http://dx.doi.org/10.1016/j.annemergmed.2006.03.030

[64] Yaqoob M. The perceptions and practices of madraseh and government school teachers about critical thinking. Master's thesis, Aga Khan University. Institute of education, Karachi. 2010.

[65] Cassum S H. Perceptions and Practices of Critical thinking amongst faculty of nursing, medicine and education in Karachi, Pakistan. Master's Thesis, The Aga Khan University, School of nursing and midwifery, Karachi 2011. 